\title{
The best machine for the money
}

\section{Washington}

REBOUNDING from their failure to obtain federal funding for a $\$ 1,500$ million burning plasma experiment (BPX), magnetic fusion scientists in the United States are closing ranks behind a machine that they think the government can afford.

The search for an alternative to the BPX may represent a new way to fund big science. Rather than coming up with an idea and trying to persuade politicians to support it, fusion scientists have worked furiously since last fall to find a project that will cost no more than the US Energy Department has decided it wants to spend at present on the long-range search for a technology that will generate more energy than it consumes.

The result is a machine that may be driven more by economics than by science. While it would maintain a US presence in magnetic fusion over the next decade, both scientifically and commercially, it falls far short of what many scientists would like to accomplish.

"Yes, this is a backwards approach to doing science," says Stephen Dean, president of Fusion Power Associates, which lobbies for the industry. "But we are living in an upside-down world, in which financial considerations take precedence over good science."

Next week, a task force will submit a report to an advisory committee on fusion energy that is expected to recommend that the government build a $\$ 400$-million Tokamak Plasma Experiment (TPX) at Princeton University. Princeton was to be the site for the cancelled BPX, and its scientists already operate the leading US tokamak.

The TPX, which has also been referred to as the steady-state advanced tokamak, would operate for up to thousands of seconds. That is a relatively long period of time compared to current efforts, which apply a brief pulse of enormous energy to the superheated plasma. It will use superconducting magnets to achieve the power- ful fields needed to keep the plasma confined. Researchers hope the experiment will provide clues about the conditions in which ignition, a sustained fusion reaction that uses a mixture of deuterium and tritium, would be possible.

The BPX, on the other hand, was intended to reach ignition as a demonstration of the feasibility of a fusion nuclear reactor. Building such a reactor is the ultimate goal of a joint US, European, Russian, and Japanese effort called the International Thermonuclear Experimental Reactor (ITER). That reactor will be a $\$ 6,000$ million programme carried out in several stages and sites over the next 30 years.

Some scientists are still hoping for a machine, much more expensive than the TPX, that could address the technical aspects of achieving ignition as well as the underlying scientific questions. Such a machine, says Ron Parker of the Massachusetts Institute of Technology, would give the country more bang for its fusion buck.

"I see it as a choice between spending $\$ 750$ million for a machine that can generate energy and spending $\$ 400$ million for a machine that just does physics", he says. "And I'm afraid that, if they back TPX, that decision will close out any discussion of the subject for the next 10 to 15 years."

But most researchers believe that they do not have that option. They argue that the Energy Department would reject any proposal above the $\$ 500$-million limit recommended last fall by the Townes committee (named after its chairman, Charles Townes of Princeton). That recommendation was based on a projected real growth of 5 per cent in the annual budget for magnetic fusion.

"If Congress says that we can have a 10 per cent real increase, then I'd say, 'Let's look at Parker's machine'," says David Baldwin from Lawrence Livermore $\mathrm{Na}$ tional Laboratory, who is chairman of the task force reporting to the Fusion Energy Advisory Committee. "But if we asked for a billion-dollar machine", which Baldwin says may be too low for what Parker wants to build, "we'd be sent packing."

There is also an element of make-work in the proposed TPX. Existing experiments at Princeton will be winding down within a few years, says William Happer, head of the Office of Energy Research, and the research team there needs TPX if it is to remain intact. In addition, US companies need to hone their skills on TPX to remain in the running for the much larger contracts that will be awarded if ITER is ever built.

"Unless you have a national capability," says Happer, "you can't participate meaningfully in an international effort. We have to teach our industry to build superconducting magnets and vacuums, and the best way is to do it. That's what the Europeans are doing."

The government has requested $\$ 20$ million in 1993 to move ahead with plans for the TPX. Advocates say that at its peak TPX will cost the Energy Department roughly $\$ 80$ million annually, and that it could be running as early as 2000 if construction begins in 1994.

Many scientists are nevertheless worried that the TPX will, like its predecessors, again fall short of its goals. "You can't hide the fact that what you can do for $\$ 400$ million is a lot less than what you can do for $\$ 1.5$ billion", says Keith Thomassen, a fusion researcher at Livermore. And with each experiment more expensive than the last, there is fear that the federal government will one day decide that the necessary next step is too costly.

"We've been saying for a long time that fusion power is at least 30 years away", says Peter Politzer of General Atomics Corp. in San Diego, California, which operates the D-III-D tokamak machine. "And it would be a very dismaying prospect if we had to come back to Congress after finishing with the TPX and say that we need $\mathrm{X}$ billion dollars more, and that fusion is still 30 years away."

Jeffrey Mervis

\section{Fusion on $\$ 2$ a day}

For the price of a single US researcher, the US Department of Energy (DOE) will support for a year a team of 116 physicists and their fusion experiments. An agreement was worked out last month between DOE, the US fusion contractor General Atomics Corp. of San Diego, and the Russian Kurchatov Institute in Moscow.

The one-year, $\$ 90,000$ contract (about $\$ 2$ a day for each of the Russian scientists), will maintain a five-year collaboration between General Atomics and the researchers at the Kurchatov Institute. Since establishing working ties in the late 1980 s, the researchers have visited each other often and now communicate regularly, says Michael Roberts, director of international programmes in the DoE office of fusion energy. Unlike its military cousin, inertial confinement fusion, magnetic fusion research has been unclassified since the 1950 s.
The two teams are already working on complementary projects - both laboratories have tokamak fusion reactors and are concentrating on the problem of confining plasma with magnetic fields. Especially enticing to DOE was the fact that the Russian machine - known as T-10 - also has the world's most powerful plasma heater.

"What they have to offer is a working facility doing what we want done", says Roberts. "It's not a sustainable situation, obviously, but it's a good opportunity now."

Other groups at the Kurchatov institute are also seeking similar subsidies from the West (see Nature 351, 683; 1991). But this is thought to be the first time that the US government has agreed to the direct support of research in the former Soviet Union.
Christopher Anderson 